\title{
Evaluating the intention to use ICT collaborative tools in a social constructivist environment
}

\author{
David Kwok ${ }^{1}$ and Silin Yang ${ }^{2^{*}}$
}

\author{
* Correspondence: \\ valyangsilin@gmail.com \\ ${ }^{2}$ Institute for Adult Learning, 1 Kay \\ Siang Road, Singapore 248922, \\ Singapore \\ Full list of author information is \\ available at the end of the article
}

\begin{abstract}
This study examined student acceptance to adopt and use ICT tools in a problembased learning module using the Technology Acceptance Model (TAM). The objectives of the study are to (a) determine if the TAM is a valid model to explain students' intentions to use ICT tools, and (b) identify the determinants of students' intention to use ICT tools. A total of 737 first-year polytechnic students completed a 13-item online questionnaire based on the TAM constructs comprising perceived ease of use, perceived usefulness, attitude toward use, and intention to use. Results obtained using structural equation modelling showed that (a) perceived ease of use significantly influenced perceived usefulness; (b) both perceived ease of use and perceived usefulness significantly influenced intention to use; and (c) both perceived usefulness and attitude toward use significantly influenced intention to use . Overall, the TAM is a valid model to help explain students' intentions to use ICT tools. The study findings are useful for PBL educators intending to integrate ICT tools in their lessons to better engage students in active learning.
\end{abstract}

Keywords: Problem based learning, ICT tools, Technology acceptance model

\section{Introduction}

In the last two decades, the rapid development and widespread implementation of Information and Communication Technologies (ICT) in education is well recognized. ICT is an "all encompassing term that includes the full gamut of electronic tools by means of which we gather, record and store information, and by means of which we exchange and distribute information to others" (Anderson, 2010; p.4). Today, the use of ICT tools such as laptop computers, electronic pads, smart phones, along with the broadband internet, interactive Web 2.0 technologies and cloud applications have enhanced both, teaching and learning in the schools (Barak \& Ziv, 2013).

The integration of technology in educational systems of many countries is recognised as a key driver to enhance teaching and learning, and educational policy-makers had invested heavily in building and maintaining ICT infrastructure in the schools (Pelgrum, 2001). In Singapore, three ICT Masterplans for the schools (1999-2014) were developed and implemented by the Ministry of Education to prepare students for the knowledge economy by harnessing ICT to transform learners towards developing twenty-first century competencies and skills. With the implementation of the three

(c) The Author(s). 2017 Open Access This article is distributed under the terms of the Creative Commons Attribution 4.0 International License (http://creativecommons.org/licenses/by/4.0/), which permits unrestricted use, distribution, and reproduction in any medium, provided you give appropriate credit to the original author(s) and the source, provide a link to the Creative Commons license, and indicate if changes were made. 
ICT Masterplans, Teo and Ting (2010) noted that improvements were made from quantity of ICT use to quality of its use by teachers and students. There was also a progressive shift from a primarily didactic, teacher-centred teaching to a more learnercentred, constructivist pedagogy in the schools.

Pelgrum and Voojt (2009) suggested the use of ICT is not about introducing a new tool in education, but the integration of ICT in educational practice has the potential to facilitate new pedagogical approaches and learner-centred educational practices. There is a substantial body of research showing the positive effects of ICT used in education such as increased student motivation and engagement, independent learning, supporting of creativity, promotion of collaborative learning, development of higherorder critical thinking skills and problem solving abilities (Condie \& Munro, 2007; Friedman \& Coates, 2009; Fu, 2013; Gallagher, Shear, Patel, \& Miller, 2011). One pedagogical approach using problem-based learning provides vast opportunities for educators to employ ICT tools to support and enhance teaching and learning.

\section{Literature review}

\section{Integration of ICT in Problem-based Learning}

Problem-based learning (PBL) adopts a social constructivist approach which seeks to create a learning environment where students learn in the context of meaningful problems, actively construct mental models, co-construct ideas with peers working collaboratively in teams, and develop self-directed learning skills in the process (Hmelo-Silver, 2004; Norman \& Schmidt 1992; Schmidt \& Moust 2000). There is a plethora of studies on how ICT tools are employed to support collaborative learning, knowledge construction and critical thinking, participation and diversifying ideas, scaffolding of concepts, and enabling self-reflection in PBL (e.g. Hack, 2013; Ioannou, Brown, \& Artino, 2015; Tambouris et al., 2012). Chai and Wang (2010) suggested various ways where ICT tools could be integrated with the PBL process to aid students' learning. For instance, students solving an authentic problem using multimedia or flash movie; employing wikis to scaffold their learning; using internet to search for information; participating in online forum or chat tools to discuss ideas; utilising knowledge forum or online discussion board to share information, negotiate ideas and construct knowledge; and using mind mapping tools to build knowledge by connecting concepts.

Despite the numerous studies on the pervasive use of ICT tools in PBL, there is limited study to evaluate students' intention to use these tools in the social constructivist pedagogy, particularly for first-year polytechnic students transitioning to PBL. Hence, this study addressed the gap in the literature by applying and testing a model to gain insights into the factors that influence students' intention to use new technologies in PBL.

\section{Technology Acceptance Model}

In the past two decades, many researchers have attempted to provide theoretical models to explain and predict users' acceptance of information technology and information system (e.g. Ajzen, 1991; Ajzen \& Fishbein, 1980; Davis, 1989; Davis et al., 1989). Among these models, the Technology Acceptance Model (TAM) is believed to 
be one of the most well-researched, robust and parsimonious model in predicting user acceptance of technology (Cornell et al., 2011; Venkatesh \& Davis, 2000).

The TAM, developed by Davis et al. (1989), traced its roots to the Theory of Reasoned Action (TRA) (Ajzen \& Fishbein, 1980; Fishbein \& Ajzen, 1975). The TRA posits that beliefs influence attitude, which in turn leads to intention, and then guide behaviour. The TAM adapted this belief-attitude-intention-behaviour relationship to a model on acceptance of new technology. In the TAM (as seen in Fig. 1), there are 2 specific variables, namely perceived usefulness and perceived ease of use, which were hypothesised as key determinants of a user's acceptance.

The TAM suggested that when users are presented with a new technology, two factors, namely perceived usefulness and perceived ease of use would influence their decisions to accept or reject it. Davis (1989) defines perceived ease of use as the degree to which an individual believes that a particular technology would be free of mental effort, whereas perceived usefulness is defined as the degree to which an individual believes that a particular technology would enhance his or her job performance. The TAM posits that perceived ease of use and perceived usefulness are major determinants of an individual's attitude toward using a new technology, and thus has an influence on intention to use it, which in turn, affects its actual use (Davis, Bagozzi \& Warsaw, 1989). In addition, perceived usefulness depends on perceived ease of use, and has a direct influence on intention to use the new technology (Teo \& Schaik, 2009; Wong, Osman, Goh, \& Rahmat, 2013). Finally, perceived ease of use and perceived usefulness are influenced by external variables such as system characteristics, user training, user participation design, and the nature of the implementation process (Venkatesh \& Davis, 1996).

Numerous studies have employed the TAM to explain the adoption and use of ICT tools among student users (e.g. Camarero, Rodríguez, \& San José, 2012; PadillaMeléndez, Garrido-Moreno, \& Del Aguila-Obra, 2008; Shroff, Deneen, \& Ng, 2011; Sumak, Heriko, Pusnik \& Polancic, 2011; Teo, 2009; Wong \& Teo, 2009). In a study on evaluating the use of different Google applications tools to facilitate collaborations among undergraduate students, Cheung and Vogel (2013) found that both perceived usefulness and perceived ease of use were significant determinants of attitudes towards usage, which in turn, led to significant effect on behavioural intention to use these tools. Perceived ease of use was found to predict perceived usefulness, and was a stronger predictor of attitude than perceived usefulness. Due to highly interactive and collaborative platforms such as Google applications, Cheong and Vogel (2013) suggested that ease of use was important, and adoption of the collaborative technologies was strongly affected by peer influence.

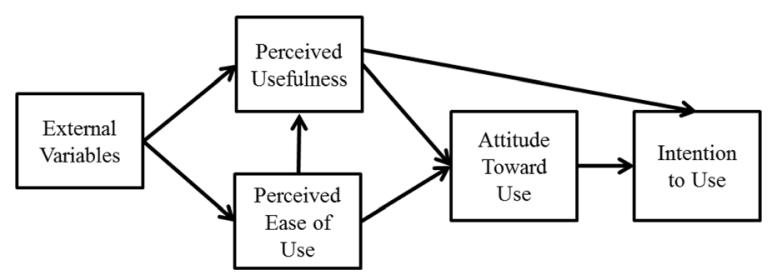

Fig. 1 Technology Acceptance Model (adapted from Davis, Bagozzi \& Warsaw, 1989) 
In another study of online forums as collaborative learning tools, Camerero, Rodríguez, and San José (2012) found that students' attitude toward use depended on whether they perceived forums to be useful and not their ease of use.

\section{Research Questions and Hypotheses}

Despite the extensive empirical studies using the TAM, Hu, Chau, Liu and Tam (1999) proposed that additional efforts are needed to validate existing research results, particularly those involving different technologies, users, and organisational contexts. Hence, this study stems from a response to the call for a more empirical validation of a well-researched model in different settings. In particular, we examined the TAM in the context of first-year polytechnic students' acceptance of ICT tools to support their learning as they transitioned to the new PBL environment from the traditional classroom learning. The research questions of this study are as follows:

1. What are the determinants of students' intention to use ICT tools based on the TAM?

2. Is the TAM a valid model to explain students' intention to use ICT tools?

In accordance with the research objectives, and consistent with the related literature, we propose the research model as shown in Fig. 2, and its five hypotheses for establishing the relationships among the four TAM constructs as follows:

$\mathrm{H}_{1}$ : Perceived ease of use will have a significant influence on perceived usefulness.

$\mathrm{H}_{2}$ : Perceived ease of use will have a significant influence on attitude toward use.

$\mathrm{H}_{3}$ : Perceived usefulness will have a significant influence on attitude toward use

$\mathrm{H}_{4}$ : Perceived usefulness will have a significant influence on intention to use.

$\mathrm{H}_{5}$ : Attitude toward use will have a significant influence on intention to use.

\section{Methodology}

\section{Participants}

Participants were 737 first-year students of a particular polytechnic taking a foundational module on Cognitive Problem Solving in the second semester. Among the participants, $446(60.5 \%)$ were females and $291(39.5 \%)$ males. Their mean age was 17.36 years

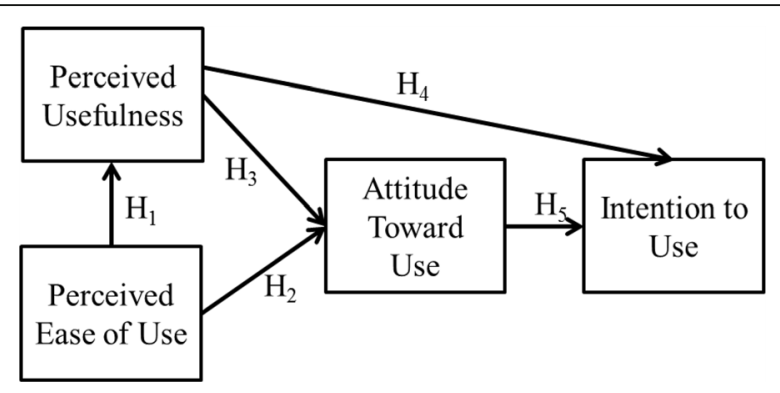

Fig. 2 Proposed research model 
$(\mathrm{SD}=1.50)$. All of the students owned and used laptops during the lessons in school, and they have access to various ICT tools to support their learning during the PBL lessons.

\section{Educational Context}

This study was conducted in a polytechnic in Singapore which delivers more than 230 different modules each semester from a wide range of diplomas in various fields. Learning typically takes place using a PBL approach where a problem scenario is presented to a class of 25 students, who work in small teams of five alongside their assigned class facilitator, once a week over a period of 13 weeks. Each PBL day is typified by a schedule of three meetings with facilitator interaction, and interspersed by two periods of self-study (O'Grady, Yew, Goh, \& Schmidt, 2012). The module chosen for this study is a compulsory first-year general module on Cognitive Processes and Problem Solving that all polytechnic students enrolled in. During the lessons, students were introduced to the various types of ICT to support their collaborative learning in teams. For instance, students used Google Apps to analyse the problem in teams, Popplet to perform a mind map to generate ideas, and Edmodo to participate in the online discussion.

\section{Measures}

A questionnaire employed in this study comprised of validated items adapted from several empirical studies using the TAM (e.g. Davis, 1989; Teo, 2009; Venkatesh, Morris, Davis, \& Davis, 2003) by replacing 'computers' with 'ICT tools' in the questionnaire. The questionnaire was reviewed by a panel of lecturers for face and content validity. It comprises 13 statements on perceived ease of use (3 items), perceived usefulness (3 items), attitude toward use (3 items) and intention to use (4 items). Participants were asked to give their responses to each of the statement on a 5-point Likert scale, ranging from 1 (strongly disagree) to 5 (strongly agree). When answering the questions in the questionnaire, the respondents were asked to relate their experience using ICT tools (e.g. Google applications, Edmodo, Popplet etc.) during the PBL lessons. Demographic data such as gender and age were also collected in the questionnaire.

\section{Data Collection}

Participants from the various classes completed the online questionnaire during the middle of the second semester with the assistance of the lecturers who administered the questionnaire in class. All participants were briefed on the purpose of the study, and were informed that their participations were strictly voluntary and anonymity safeguarded. The participants have the rights not to participate or withdraw from the study any time. Participants were also informed that no module credit will be given for participating in the study and their responses do not affect their assessment grades. On average, the respondents took not more than $20 \mathrm{~min}$ to complete the questionnaire.

This research study was approved by the Ethics Review Committee at the institution where the research was undertaken. The approved research protocol included informed consent by the participants, controlled storage and access of data, and de-identified data for analysis. 


\section{Results}

The analysis of the study was carried out in two stages using a measurement model and structural model (Anderson \& Gerbing, 1998; Hair et al., 2009). The first stage involved building a measurement model based on a confirmatory factor analysis (CFA), and examining the descriptive statistics, and assessing the validity and reliability. The second stage involved building a structural equation model of the latent constructs, and testing the hypothesised relationships among the constructs.

\section{Descriptive Statistics}

The mean ratings of all the four constructs were between 3.54 and 3.72, and are above the mid-point of 3.00 of the scale (see Table 1). This indicated an overall favourable response to the constructs measured in the study. The standard deviations ranged from 0.75 to 0.85 , which revealed a narrow spread around the mean. The skewness ranged from - 0.58 to -0.18 and kurtosis ranged from 0.40 to 0.91 were all within Kline's (2005) suggested cut-offs of absolute values greater than 3 and 10 respectively, indicating that the data were normally distributed and thus suitable for the purpose of structural equation modelling.

\section{Test of Measurement Model}

The measurement model is tested using structural equation modelling (SEM) using AMOS 18.0 software (Arbuckle, 2009). Structural equation modelling is a multivariate technique that combines factor analysis and multiple regressions to simultaneously examine a series of interrelated dependence relationships among measured variables and latent variables as well as several latent constructs (Hair et al., 2009). Maximum likelihood estimation is used in SEM to generate a full-fledged measurement model and it is a robust estimation method, capable of handling large sample size and distribution that deviates from normality (Arbuckle, 2009).

\section{Exploratory Factor Analysis}

The items were subjected to Principle Component Factor (PCF) analysis with oblique (promax) rotation. Four factors were extracted, matching the number and description of the constructs included in the proposed TAM. The total variance explained by the four factors is $86.11 \%$. All the items had factor loadings of over 0.60 , and the present study accepted this threshold as practical significant (Hair et al., 2009).

\section{Convergent Validity}

Convergent validity of the set of measurement items was assessed using three approaches: (a) item reliability; (b) composite reliability; and (c) average variance extracted

Table 1 Descriptive statistics of the constructs

\begin{tabular}{llllll}
\hline Construct & Item & Mean & SD & Skewness & Kurtosis \\
\hline Perceived ease of use (EASE) & 3 & 3.72 & 0.75 & -0.40 & 0.50 \\
Perceived usefulness (USE) & 3 & 3.75 & 0.76 & -0.58 & 0.91 \\
Attitude toward use (ATT) & 3 & 3.54 & 0.76 & -0.18 & 0.46 \\
Intention to use (INT) & 4 & 3.60 & 0.85 & -0.42 & 0.40 \\
\hline
\end{tabular}


(Fornell \& Larcher, 1981). By inspection, the item reliability assessed by its factor loadings of the individual items into the underlying construct was between 0.72 and 0.91 (see Table 2). This exceeded the threshold of 0.50 set by Hair et al. (2009), indicating convergent validity at the item level. The composite reliability of each construct is assessed using Cronbach alpha, and a recommended alpha value of 0.70 is considered acceptable (DeVellis, 2003; Nunnally \& Bernstein, 1994). As shown in Table 2, the Cronbach alphas ranged from 0.89 to 0.92 , well above the recommended value. Finally, a more conservative test of convergent is the use of average variance extracted (AVE), the amount of variance captured by the construct in relation to the variance attributable to measurement error. As recommended by Fornell and Larcher (1981), the AVE is deemed adequate if it is equal or exceeds 0.50. As shown in Table 2, the AVEs for all constructs exceeded 0.50 , and hence convergent validity of the constructs is adequate. Hence, convergent validity for all the items and constructs in this study are adequate.

\section{Discriminant Validity}

Discriminant validity is the extent to which a construct is absolutely distinct from other constructs (Hair et al., 2009), and it can be assessed at both the item and construct levels. At the item level, Barclay, Higgins, \& Thompson (1995) proposed that discriminant validity is evident when an item correlates more highly with items in the construct it purports to measure than items belonging to other constructs. As shown in Appendix, an acceptable level of discriminant validity at the item level was found using the inter-correlations of items.

Table 2 Results of the Measurement Model

\begin{tabular}{|c|c|c|c|c|c|c|}
\hline Item & Mean & SD & Factor Loading & T-value & $\begin{array}{l}{ }^{\mathrm{a}} \mathrm{AVE} \\
(>0.50)^{*}\end{array}$ & $\begin{array}{l}\text { Cronbach's Alphas } \\
(>0.70)^{*}\end{array}$ \\
\hline Perceived ease of use & & & & & 0.83 & 0.92 \\
\hline EASE1 & 3.80 & 0.85 & 0.91 & $13.47^{* *}$ & & \\
\hline EASE2 & 3.79 & 0.84 & 0.91 & $10.76^{* *}$ & & \\
\hline EASE3 & 3.74 & 0.85 & 0.91 & $14.87^{* *}$ & & \\
\hline Perceived usefulness & & & & & 0.76 & 0.92 \\
\hline USE2 & 3.72 & 0.84 & 0.84 & $14.50^{* *}$ & & \\
\hline USE3 & 3.77 & 0.84 & 0.92 & $12.86^{* *}$ & & \\
\hline USE4 & 3.73 & 0.85 & 0.85 & $13.92^{* *}$ & & \\
\hline Attitude toward use & & & & & 0.69 & 0.89 \\
\hline ATT3 & 3.61 & 0.81 & 0.82 & $15.87^{* *}$ & & \\
\hline ATT4 & 3.47 & 0.87 & 0.94 & $13.57^{* *}$ & & \\
\hline ATT5 & 3.52 & 0.86 & 0.72 & $13.15^{* *}$ & & \\
\hline Intention to use & & & & & 0.82 & 0.96 \\
\hline INT1 & 3.66 & 0.91 & 0.87 & $10.41^{* *}$ & & \\
\hline INT2 & 3.68 & 0.88 & 0.89 & $9.93^{* *}$ & & \\
\hline INT3 & 3.53 & 0.92 & 0.94 & $12.25^{* *}$ & & \\
\hline INT4 & 3.55 & 0.90 & 0.93 & $12.93^{* *}$ & & \\
\hline
\end{tabular}


At the construct level, discriminant validity was assessed by comparing the square root of the AVE for the given construct with the correlations between that construct and all other constructs. As shown in Table 3, the square root of the AVEs were greater than the off-diagonal numbers in the rows and columns in the matrix, and this suggested that the construct is more strongly correlated with its items than with other constructs in the model. Hence, discriminant validity of all the items and constructs are acceptable, and deemed adequate for further analyses.

The fit indices for the measurement model were computed using structural equation modelling with AMOS 18.0 software (Arbuckle, 2009). A variety of indices comprising absolute fit indices ( $\chi^{2}$ statistics; goodness-of-fit index, GFI; standardised root mean residual, SRMR), parsimonious indices (root mean square error of approximation, RMSEA) and incremental fit indices (comparative fit index, CFI; Tucker-Lewis index, TLI) were employed in this study. Hair et al. (2009) noted that $\chi^{2}$ has a tendency to indicate significant differences because of its sensitivity to sample size differences and sample larger than 200 . Hence, the value of $x^{2} / \mathrm{df}$ was recommended, and the value of $\mathrm{X} 2 / \mathrm{df}<3.00$ deemed acceptable (Hair et al., 2009).

Except for the $\chi^{2}$, the results in Table 4 showed that all values of the indices satisfied the recommended level of acceptable fit $\left(\mathrm{X}^{2}=157.62, p<0.001 ; \mathrm{X}^{2} / \mathrm{df}=2.77\right.$; TLI $=0.99$; CFI $=0.99 ;$ GFI $=0.97 ;$ RMSEA $=0.05 ;$ SRMR $=0.01$ ), which provided support to proceed with testing the structural model.

\section{Testing the Structural Model}

The model fit of the structural model was again tested using different fit indices. Except for $\mathrm{X}^{2}$, all fit indices $\left(\mathrm{X}^{2}=169.72, p<0.001 ; \mathrm{X}^{2} / \mathrm{df}=2.93\right.$; TLI $=0.99$; CFI $=0.99$; GFI $=0.97$; RMSEA $=0.05$; SRMR $=0.02$ ), were acceptable to the recommended levels of fit (see Table 4).

\section{Testing the Hypotheses}

Figure 3 shows the resulting path coefficients of the research model. Perceived ease of use had a significant influence on perceived usefulness $(\beta=0.79, p<0.001)$, supporting H1. Attitude toward using ICT tools was influenced by both perceived usefulness $(\beta=0.64, p<0.001)$ and perceived ease of use $(\beta=0.21, p<0.001)$, both supporting $\mathrm{H} 2$ and $\mathrm{H} 3$. Intention to use ICT tools was found to be influenced by attitudes towards using ICT tools $(\beta=0.67, p<0.001)$ and perceived usefulness $(\beta=0.25, p<0.001)$, supporting hypotheses $\mathrm{H} 5$ and $\mathrm{H} 4$.

The explanatory power of the model for individual constructs was examined using the resulting R2 for each dependent construct. Perceived usefulness was found to be

Table 3 Discriminant validity for the measurement model

\begin{tabular}{lllll}
\hline Construct & USE & EASE & ATT & INT \\
\hline Perceived usefulness (USE) & $(.87)$ & & & \\
Perceived ease of use (EASE) & $.69^{*}$ & $(.91)$ & $(.83)$ \\
Attitude toward use (ATT) & $.68^{*}$ & $.61^{*}$ & $.74^{*}$ & $(.91)$ \\
Intention to use (INT) & $.68^{*}$ & $.64^{*}$ &
\end{tabular}


Table 4 Fit indices for the measurement and structural model

\begin{tabular}{llll}
\hline Model fit indices & $\begin{array}{l}\text { Recommended } \\
\text { levels of fit* }\end{array}$ & Values in the measurement model & Values in the structural model \\
\hline X2 statistics & Not significant & $157.62, p<0.001$ & $169.72, p<0.001$ \\
X2/df & $<3.00$ & 2.77 & 2.93 \\
TLI & $\geq 0.90$ & 0.99 & 0.99 \\
CFI & $\geq 0.90$ & 0.99 & 0.99 \\
GFI & $\geq 0.90$ & 0.97 & 0.97 \\
RMSEA & $<0.08$ & 0.05 & 0.05 \\
SRMR & $<0.08$ & 0.01 & 0.02 \\
\hline
\end{tabular}

*Sources: Kline, 2005; Hair et al., 2009

significantly determined by perceived ease of use, resulting in an R2 of $61.7 \%$. In other words, perceived ease of use explained $61.7 \%$ of the variance in perceived usefulness. Attitude towards using ICT tools was significantly determined by perceived usefulness and perceived ease of use, resulting in R2 of $66.6 \%$. The combined effect of perceived usefulness and attitude towards using ICT tools explained $77.4 \%$ of the variance of intention to use ICT tools. Table 5 shows the result of the hypotheses testing and all five hypotheses were supported.

\section{Discussion and implications}

This study attempted to apply the TAM to examine polytechnic students' intention to use of ICT tools in a PBL setting. Specifically, the study examined the influences of three constructs, namely perceived usefulness, perceived ease of use and attitude toward use on the intention to use ICT tools. Five hypotheses in the TAM were tested, and were all supported. The results showed that three constructs explained $77.4 \%$ of the total variance in students' intention to use ICT tools. Hence, the TAM is a valid and effective model to explain students' intention to use ICT tools.

Consistent with previous research (Cheong \& Vogel, 2013; Schroff, Deneen, \& Ng, 2011), perceived ease of use had a significant effect on perceived usefulness. It is

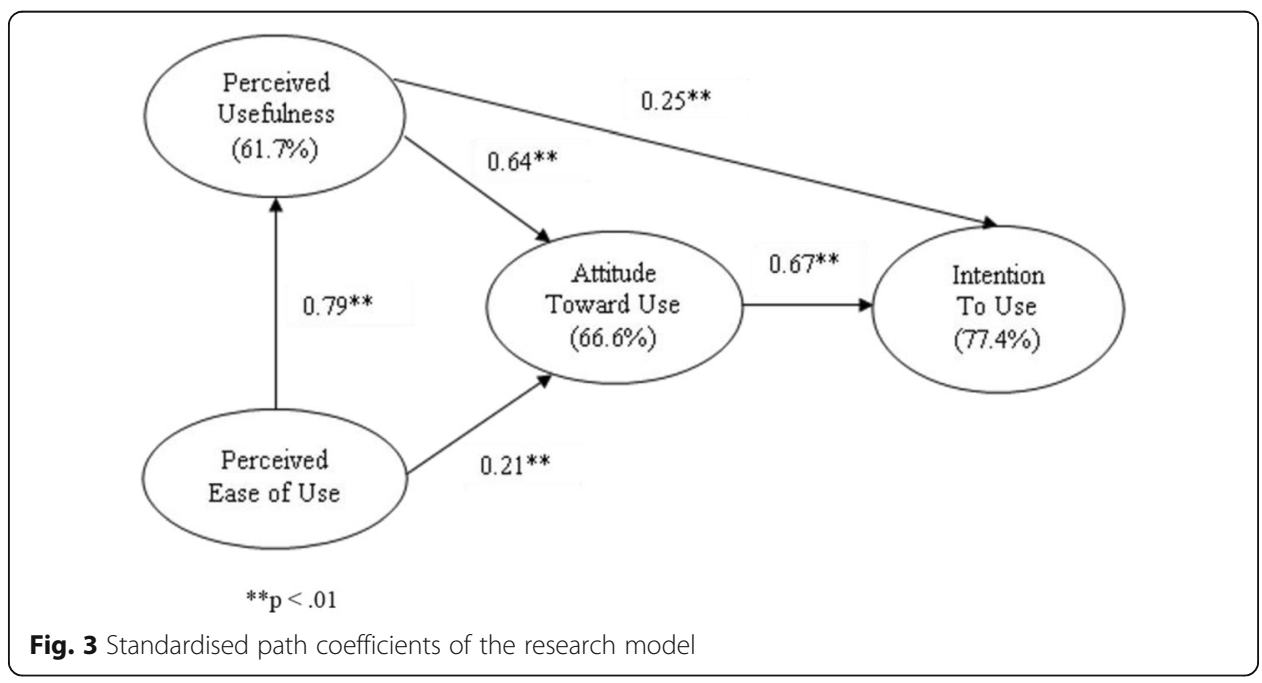


Table 5 Hypothesis testing results

\begin{tabular}{lllll}
\hline Hypothesis & Path & Path coefficient & t-value & Results \\
\hline $\mathrm{H}_{1}$ & EASE $\rightarrow$ USE & 0.785 & $22.32^{* *}$ & Supported \\
$\mathrm{H}_{2}$ & EASE $\rightarrow$ ATT & 0.213 & $4.31^{* *}$ & Supported \\
$\mathrm{H}_{3}$ & USE $\rightarrow$ ATT & 0.639 & $11.93^{* *}$ & Supported \\
$\mathrm{H}_{4}$ & USE $\rightarrow$ INT & 0.251 & $5.33^{* *}$ & Supported \\
$\mathrm{H}_{5}$ & ATT $\rightarrow$ INT & 0.665 & $12.88^{* *}$ & Supported \\
${ }^{* * *} p<.001$ & & &
\end{tabular}

noteworthy that perceived ease of use was the strongest predictor of perceived usefulness in the TAM. This result suggested that, from a practical perspective, students are likely to perceive ICT tools as useful when they think these tools do not require much mental effort to use and can be learnt by doing.

In agreement with what the TAM postulated, perceived usefulness had a significant effect on students' intention to use ICT tools. This may suggest that students are relatively 'pragmatic' and tend to focus on the usefulness of the ICT tools. Therefore, for ICT tools to be accepted by the students, it is critical for lecturers to demonstrate that these tools would help students to increase their job performance. For example, Google docs could be used as a collaborative learning tool by the students working in a team to co-construct and share ideas.

Although perceived ease of use and perceived usefulness were found to influence attitude toward use of ICT tools, it is noteworthy that perceived usefulness was a stronger predictor of attitude than perceived ease of use, consistent with previous research (e.g. Camarero, Rodríguez, \& San José, 2012; Padilla-Meléndez, Garrido-Moreno, \& Del Aguila-Obra, 2008; Shroff, Deneen, \& Ng, 2011). It appeared that the significant effect of perceived ease of use had on attitude towards usage was mediated by perceived usefulness. Davis et al. (1989) proposed that as users become more familiar and experienced with technology, perceived usefulness tended to be stronger than perceived ease of use in developing positive attitudes (or feelings) toward use. In the present study, it is plausible that students after one semester of study had developed positive feelings about the perceived usefulness of the ICT tools which helped them to be more productive in their work, acquire new knowledge and obtain better grades. Therefore, the continued and sustained use of ICT tools could contribute to positive attitude toward perceived usefulness of these tools by the students.

Students' intention to use ICT tools was influenced by their positive attitude toward use in this study. Studies suggested that attitude was a significant predictor of intention to use technology in a volitional context where users have a choice to use or not to use the technology (Winters, Chudoba, \& Gutek, 1998; Teo, Lee \& Chai, 2008; Teo, 2009). However, in the present study, it is likely that the students were 'quasi-volitional' ICT users, described as non-mandated user of ICT but not completely volitional because of social pressure and subjective norms that existed in the social and collaborative PBL environment (Rai, Lang, \& Welker, 2002).

This study has two practical implications for lecturers intending to adopt and use ICT tools in their PBL lessons. First, the higher the level of perceived usefulness of ICT tools, the greater the likelihood they will appeal to students and are encouraged to use them (Camarero, Rodríguez, \& San José, 2012). Despite the numerous benefits of using 
ICT tools to aid students' collaborative learning, communication and knowledge construction, it is pertinent that lecturers promote the perceived usefulness of the tools by demonstrating positive behaviours to maintain students' interests and participation in their usage. These included interacting with students online, giving constructive feedback, resolving technical issues, posting quality and engaging contents, resolving technical issues using the ICT tools, and ensuring the system setup is error-free. If these positive behaviours are not present, it may result in a possibility that students' perceived usefulness of the ICT tools will be undermined, and thus affecting actual usage.

Second, there is a need to promote and facilitate the use of ICT tools among the lecturers through offering training workshops in the use of these tools. When the lecturers developed self-efficacy in the use of ICT tools, they will adopt a positive attitude, which in turn, foster and facilitate students' use of ICT tools during the lesson. In instances where students encountered difficulties with the use of ICT tools, lecturers would have the confidence to resolve the issues skilfully and independently.

\section{Limitations and future research}

This study is not without limitations. First, the study employed a self-reported questionnaire which may be subjected to social desirability bias, where respondents have the tendency to over-report or under-report their responses. Future studies using a mixed methods approach comprising questionnaire and focus group interviews would give the researchers further insights into why students accept or reject the use of new technologies in PBL. Second, the three constructs in the TAM explained $77.4 \%$ of the total variance in intention to use ICT tools, leaving $22.6 \%$ unexplained. Hence, future studies could focus on extending the TAM to include other constructs such as social influence, potential user's experience and motivation (see Karahanna \& Straub, 1999; Saade \& Bahli, 2005; Venkatesh \& Davis, 2000). In addition, the study is drawn from a sample of first-year polytechnic students which took a particular module and hence care should be exercised not to generalise this study finding to the entire population of polytechnic students. Finally, the study was based on a module which lasted only 13 weeks, therefore a longitudinal study on the acceptance of ICT tools with the same cohort of students over 3 years of study would be a worthwhile future research topic to undertake.

\section{Conclusions}

This study suggests that the TAM is a parsimonious and effective model to predict polytechnic students' acceptance of ICT tools in a PBL environment. It was found that students' perceived ease of use and perceived usefulness were significant determinants of attitudes toward use which in turn predicted intention to use ICT tools. Although this study is conducted in the context of social constructivist environment using PBL, the findings should be of interests to lecturers who use ICT tools in other pedagogies and instructional activities aiming to support students' collaborative learning. As the students are advanced users of internet-based technologies and considered 'digital natives' (Gaston, 2006) who are fairly prolific users of ICT tools, future studies could focus on extending the TAM to include external variables (e.g. peer influence and perceptions of collaborative learning) to examine the acceptance of specific technology used in PBL. We proposed that training workshops be conducted for lecturers on the effective use of ICT tools to enable them to develop instructional strategies to optimise students' learning. 


\section{Appendix}

Table 6 Inter-correlations among the items

\begin{tabular}{|c|c|c|c|c|c|c|c|c|c|c|c|c|c|}
\hline & USE2 & USE3 & USE4 & EASE1 & EASE2 & EASE3 & АТT3 & ATT4 & ATT5 & INT1 & INT2 & INT3 & INT4 \\
\hline USE2 & 1 & & & & & & & & & & & & \\
\hline USE3 & $.79^{*}$ & 1 & & & & & & & & & & & \\
\hline USE4 & $.79^{*}$ & $.80^{*}$ & 1 & & & & & & & & & & \\
\hline EASE1 & $.64^{*}$ & $.61^{*}$ & $.62^{*}$ & 1 & & & & & & & & & \\
\hline EASE2 & $.65^{*}$ & $.62^{*}$ & $.65^{*}$ & $.83^{*}$ & 1 & & & & & & & & \\
\hline EASE3 & $.59^{*}$ & $.60^{*}$ & $.63^{*}$ & $.77^{*}$ & $.80^{*}$ & 1 & & & & & & & \\
\hline ATT3 & $.62^{*}$ & $.63^{*}$ & $.62^{*}$ & $.54^{*}$ & $.54^{*}$ & $.53^{*}$ & 1 & & & & & & \\
\hline ATT4 & $.60^{*}$ & $.63^{*}$ & $.60^{*}$ & $.53^{*}$ & $.50^{*}$ & $.52^{*}$ & $.72^{*}$ & 1 & & & & & \\
\hline ATT5 & $.63^{*}$ & $.61^{*}$ & $.62^{*}$ & $.58^{*}$ & $.58^{*}$ & $.57^{*}$ & $.68^{*}$ & $.78^{*}$ & 1 & & & & \\
\hline INT1 & $.64^{*}$ & $.64^{*}$ & $.64^{*}$ & $.58^{*}$ & $.60^{*}$ & $.59^{*}$ & $.63^{*}$ & $.67^{*}$ & $.73^{*}$ & 1 & & & \\
\hline INT2 & $.61^{*}$ & $.65^{*}$ & $.65^{*}$ & $.59^{*}$ & $.59^{*}$ & $.58^{*}$ & $.64^{*}$ & $.68^{*}$ & $.72^{*}$ & $.89^{*}$ & 1 & & \\
\hline INT3 & $.61^{*}$ & $.61^{*}$ & $.62^{*}$ & $.59^{*}$ & $.60^{*}$ & $.59^{*}$ & $.64^{*}$ & $.66^{*}$ & $.70^{*}$ & $.83^{*}$ & $.84^{*}$ & 1 & \\
\hline INT4 & $.61^{*}$ & $.63^{*}$ & $.63^{*}$ & $.55^{*}$ & $.56^{*}$ & $.56^{*}$ & $.63^{*}$ & $.66^{*}$ & $.70^{*}$ & $.81^{*}$ & $.82^{*}$ & $.89^{*}$ & 1 \\
\hline
\end{tabular}

${ }^{*} p<0.01$

Acknowledgements

Not applicable.

\section{Funding}

No funding was involved.

Availability of data and materials

Data can be shared by authors if requested.

\section{Authors' contributions}

Both authors were involved in the development of the manuscript. Both authors read and approved the final manuscript.

\section{Ethics approval and consent to participate}

This research study was approved by the Ethics Review Committee at the institution (Republic Polytechnic, Singapore) where the research was undertaken. The approved research protocol included informed consent by the participants, controlled storage and access of data, and de-identified data for analysis.

\section{Consent for publication}

No applicable

\section{Competing interests}

The authors declare that they have no competing interests.

\section{Publisher's Note}

Springer Nature remains neutral with regard to jurisdictional claims in published maps and institutional affiliations.

\section{Author details}

${ }^{1}$ Centre for Educational Department, Republic Polytechnic, 9 Woodlands Avenue 9, Singapore 738964, Singapore.

${ }^{2}$ Institute for Adult Learning, 1 Kay Siang Road, Singapore 248922, Singapore.

Received: 18 May 2017 Accepted: 21 July 2017

Published online: 04 September 2017

\section{References}

Ajzen I. (1991). The theory of planned behaviour. Organisational Beha-ior and Human Decision Processes, 50, 179-211.

Ajzen I., \& Fishbein M. (1980). Understanding attitudes and predicting social behaviour. Englewood Cliffs, NJ: Prentice Hall.

Anderson J. C., \& Gerbing D. W. (1998). Structural equation modeling in practice: A review and recommended two-step approach. Psychological Bulletin, 103, 411-423.

Anderson, J. (2010). ICT transforming education: A regional guide. UNESCO Bangkok.

Arbuckle J. (2009). Amos 18 user's guide. Armonk, New York, USA: SPSS Incorporated. 
Barak M., \& Ziv S. (2013). Wandering: A Web-based platform for the creation of location-based interactive learning objects. Computers \& Education, 62, 159-170.

Barclay D., Higgins C., \& Thompson R. (1995). The Partial Least Squares (PLS) Approach to Causal Modeling: Personal Computer Adoption and Use as an Illustration. Technology Studies, 2(2), 285-309.

Camarero C., Rodríguez J., \& San José R. (2012). An exploratory study of online forums as a collaborative learning tool. Online Information Review, 36(4), 568-586.

Chai, C. S., \& Wang, Q. (Eds.) (2010). ICT for self-directed and collaborative learning. Pearson/Prentice Hall.

Cheung R., \& Vogel D. (2013). Predicting user acceptance of collaborative technologies: An extension of the technology acceptance model for e-learning. Computers \& Education, 63, 160-175.

Condie, R., \& Munro, B. (2007). The impact of ICT in schools: Landscape review. British Educational Communications and Technology Agency (BECTA).

Cornell R. M., Eining M. M., \& Hu P. J. H. (2011). The effects of process accountability on individuals' use of a familiar technology. Journal of Information Systems, 25(1), 109-128.

Davis F. D. (1989). Perceived usefulness, perceived ease of use, and user acceptance of information technology. MIS Quarterly, 13(3), 319-340.

Davis F. D., Bagozzi R. P., \& Warshaw P. R. (1989). User acceptance of computer technology: a comparison of two theoretical models. Management Science, 35(8), 982-1003.

DeVellis R. F. (2003). Scale development: Theory and applications. (L. B. and D. J. Rog, Ed.), SAGE publication Ltd (Third edit). SAGE.

Fishbein M., \& Ajzen I. (1975). Beliefs, attitude, intention and behavior: An introduction to theory and research. Reading, MA: Addison-Wesley.

Fornell C., \& Larcker D. F. (1981). Evaluating structural equation models with unobservable variables and measurement error. Journal of Marketing Research, 18(1), 39-50.

Friedman T., \& Coates H. (2009). School connections: Using ICT to engage students in learning. Sydney: Microsoft Corporation.

Fu J. S. (2013). ICT in education: A critical literature review and its implications. International Journal of Education and Development using Information and Communication Technology, 9(1), 112.

Gallagher L., Shear L., Patel D., \& Miller G. (2011). ITL Research Phase I: Technical supplement. Seattle, WA: Microsoft.

Hack C. (2013). Using Web 2.0 Technology to Enhance, Scaffold and Assess Problem-Based Learning. Journal of Problem Based Learning in Higher Education, 1(1), 230-246.

Hair J. F. Jr., Black W. C., Babin B. J., \& Anderson R. E. (2009). Multivariate data analysis: A global perspective (7th ed., ). Upper Saddle River: Prentice Hall.

Hu P. J., Chau P. Y. K., Liu-Sheng O. R., \& Yan-Tam K. (1999). Examining the technology acceptance model using physician acceptance of telemedicine technology. Journal of Management Information Systems, 16(2), $91-112$.

Gaston J. (2006). Reaching and teaching the digital natives. Library Hi Tech News, 23(3), 12-13.

Hmelo-Silver C. E. (2004). Problem-based learning: What and how do students learn? Educational Psychology Review, 16(3), 235-266.

loannou A., Brown S. W., \& Artino A. R. (2015). Wikis and forums for collaborative problem-based activity: A systematic comparison of learners' interactions. The Internet and Higher Education, 24, 35-45.

Karahanna E., \& Straub D. W. (1999). The psychological origins of perceived usefulness and ease-of-use. Information Management, 35(4), 237-250.

Kline R. B. (2005). Principles and practice of structural equation modeling (2nd ed., ). New York: Guilford Press.

Norman G. R., \& Schmidt H. G. (1992). The psychological basis of problem-based learning: A review of the evidence. Academic Medicine, 67(9), 557-565.

Nunnally J. C., \& Bernstein I. H. (1994). Psychometric Theory. New York: McGraw-Hill.

O'Grady G., Yew E. H. J., Goh K. P. L., \& Schmidt H. G. (2012). One-day, one-problem: an approach to problem-based learning. One-Day, One-Problem: An Approach to Problem-based Learning (pp. 1-298). Springer Singapore. https://doi.org/10.1007/978-981-4021-75-3.

Padilla-Meléndez A., Garrido-Moreno A., \& Del Aguila-Obra A. R. (2008). Factors affecting e-collaboration technology use among management students. Computers \& Education, 51(2), 609-623.

Pelgrum W. J. (2001). Obstacles to the integration of ICT in education: results from a worldwide educational assessment. Computers \& Education, 37(2), 163-178.

Pelgrum W. J., \& Voogt J. (2009). School and teacher factors associated with frequency of ICT use by mathematics teachers: Country comparisons. Education and Information Technologies, 14(4), 293-308.

Rai A., Lang S. S., \& Welker R. B. (2002). Assessing the validity of IS success models: An empirical test and theoretical analysis. Information Systems Research, 13(1), 50-69.

Saadé R., \& Bahli B. (2005). The impact of cognitive absorption on perceived usefulness and perceived ease of use in on-line learning: an extension of the technology acceptance model. Information Management, 42(2), 317-327.

Schmidt H. G., \& Moust J. H. C. (2000). Factors affecting small-group tutorial learning: A review of research. In D. H. Evensen, \& C. E. Hmelo-Silver (Eds.), Problem-based learning: A research perspective on learning interactions (pp. 1952). Mahwah, NJ: Lawrence Erlbaum.

Shroff R. H., Deneen C. D., \& Ng E. M. (2011). Analysis of the technology acceptance model in examining students' behavioural intention to use an e-portfolio system. Australasian Journal of Educational Technology, 27(4), 600-618.

Sumak B., Hericko M., Pusnik M., \& Polancic G. (2011). Factors affecting acceptance and use of Moodle: An empirical study based on TAM. Informatica, 35, 91-100.

Tambouris E., Panopoulou E., Tarabanis K., Ryberg T., Buus L., Peristeras V., Lee D., \& Porwol L. (2012). Enabling problem based learning through Web 2.0 technologies: PBL 2.0. Educational Technology \& Society, 15(4), 238-251.

Teo T., Lee C. B., \& Chai C. S. (2008). Understanding pre-service teachers' computer attitudes: applying and extending the technology acceptance model. Journal of Computer Assisted Learning, 24(2), 128-143. 
Teo T. (2009). Evaluating the intention to use technology among student teachers: A structural equation modeling approach. International Journal of Technology in Teaching and Learning, 5(2), 106-118.

Teo Y. H., \& Ting B. H. (2010). Singapore education ICT masterplans (1997-2004). In C. S. Chai, \& Q. Wang (Eds.), ICT for self-directed and collaborative learning (pp. 2-14). Pearson Education.

Venkatesh V., \& Davis F. D. (1996). A model of the antecedents of perceived ease of use: Development and test. Decision Sciences, 27(3), 451-481.

Venkatesh V., \& Davis F. D. (2000). A theoretical extension of the technology acceptance model: Four longitudinal field studies. Management Science, 46(2), 186-204.

Venkatesh V., Morris M. G., Davis G. B., \& Davis E. D. (2003). User Acceptance of Information Technology: Towards a Unified View. MIS Quarterly, 27(3), 425-478.

Winter S., Chudoba K., Gutek B. (1998). Attitudes Toward Computers: When Do They Predict Computer Use. Information \& Management, 34(5), 275-284.

Wong K.-T., Osman B. R., Goh P. S. C., \& Rahmat M. K. (2013). Understanding student teachers' behavioural intention to use technology: technology acceptance model (TAM) validation and testing. International Journal of Instruction, 6(1), 89-104.

Submit your manuscript to a SpringerOpen ${ }^{\circ}$ journal and benefit from:

- Convenient online submission

- Rigorous peer review

- Open access: articles freely available online

- High visibility within the field

- Retaining the copyright to your article

Submit your next manuscript at $\gg$ springeropen.com 